\title{
Advanced Lead-Acid Batteries - the Way forward for Low-Cost Micro and Mild Hybrid Vehicles
}

\author{
A Cooper ${ }^{1}$, P Moseley $^{2}$ \\ ${ }^{1}$ European Advanced Lead-Acid Battery Consortium, 17a Welbeck Way, London W1G 9YJ. UK. acatcorfe@aol.com \\ ${ }^{2}$ Advanced Lead Acid Battery Consortium, PO Box 12036, Research Triangle Park, NC 27709, USA. \\ pmoseley@ilzro.org
}

\begin{abstract}
The Advanced Lead Acid Battery Consortium has been researching into VRLA batteries since 1992, initially for electric vehicle (EV) applications, where it achieved significant life extension in deep cycle duty. More recently it has focussed its work on hybrid electric vehicle (HEV) applications where the battery has to operate in High-Rate Partial State-of-Charge (HRPSoC) conditions. Whereas in EV operation failure occurs in the positive plate, in HEV duty, failure is due to negative plate sulfation, resulting in rapid loss of capacity. Ways of overcoming this have been investigated successfully and the $\mathrm{ALABC}$ is undertaking vehicle demonstration programmes to publicise this work.
\end{abstract}

Keywords: Valve-regulated lead-acid,, Bipolar, HEV (Hybrid Electric Vehicle)

\section{Introduction}

In a hybrid electric vehicle, the battery has to be maintained in a partial state-of-charge (PSoC) so that it can both accept regenerative charging and also deliver power to assist in propulsion of the vehicle without the battery becoming overcharged or over-discharged. In this type of application, the failure mode of the lead-acid battery occurs in the negative plate and is due to a progressive build up of lead sulfate in the negative active material. This gradually leads to a loss of capacity and hence the ability to provide power when needed.

Therefore ALABC research activity has concentrated on ways of avoiding this degradation of the negative plate. These included:

- Periodic conditioning of the battery i.e. routinely bringing it up to full state-ofcharge.
- Proper battery management to keep high voltage strings in balance.

- Improved grid design to enhance charge acceptance and discharge ability.

- Modifications to the negative plate chemistry and, more specifically, the addition of carbon to the negative active material.

All this work has been very successful and has resulted in very significant lifetime and performance improvements to the lead-acid battery in this application. Only recently however has the key role of carbon in the negative plate begun to be appreciated even if it is not yet fully understood. Successful laboratory demonstration of significantly improved performance has resulted in the Advanced Lead Acid Battery Consortium committing not inconsiderable funds towards demonstrating these batteries in vehicles. The objectives in undertaking this demonstration programme can be described as follows: 
- To evaluate the performance of the new generation of advanced lead-acid batteries in extended and representative duty.

- To build an in-depth understanding of the hybrid application.

- To develop the system solution that will be required by the OEMs

- To raise awareness of the significantly more cost-efficient energy storage option provided by advanced lead-acid batteries.

The success of these tests in Honda Insights is described in this paper together with details of the conversion of a current Honda Civic to operate with an Effpower bipolar lead-acid battery.

\section{The Insight Programmes}

\subsection{The RHOLAB Project}

This project has been previously reported [1], [2] and in essence involved the development of a novel, spirally-wound $2 \mathrm{~V}$ cell based on a Hawker Cyclon 8Ah cell to serve as the building block for a $144 \mathrm{~V}$ HEV battery. These cells were mounted into specially designed $36 \mathrm{~V}$ modules with full monitoring of voltage, current and temperature and controlled in such a way that each cell could be individually conditioned as necessary. At the time of conception of this project, the ALABC work on negative plate chemistry had not reached the state where the concept of conditioning could be abandoned. Figure 1 shows the four modules fitted in the vehicle.

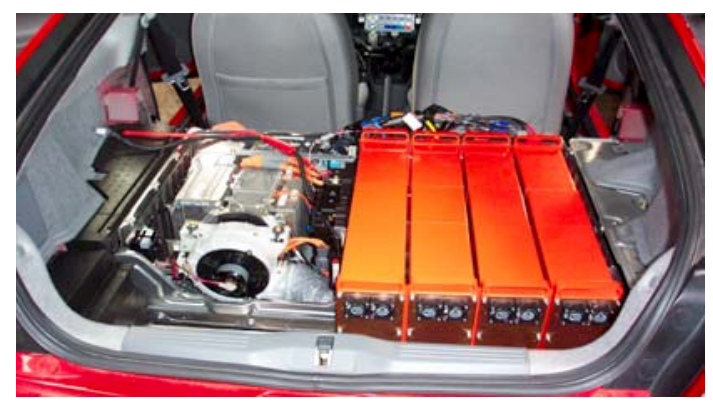

\section{Figure 1: Rholab modules in the vehicle}

After extensive shake down work to resolve software issues in the battery management system and to integrate it with the Honda electronics, the vehicle was then ready for its extended road test at Millbrook Proving Ground in the UK. This started in August 2006 and after a few problems with its associated electronics and hardware, reached the intended target of 80,000 $\mathrm{km}$ on August $15^{\text {th }} 2007$. As this was by this time seen as very much a 'generation 1' battery requiring periodic conditioning, the test was terminated. During the test period there were some minor battery pack issues, such as a relay shorting and a cooling fan failure but, by and large, the battery ran well despite not having been produced with the now preferred negative plate chemistry. As the trial went on, much was learnt about the battery management system and the integration into the vehicle electronics and the whole system was engineered to become much more reliable.

This concept of utilising an VRLA battery with a battery management system, with routine conditioning of the battery, is being utilised by BMW in their EfficientDynamics Stop/Start system [3].

\subsection{The Effpower Project}

The ALABC has used the expertise obtained in the RHOLAB project to convert two other Insights with state-of-the-art lead-acid batteries. One has been converted by EffPower in Sweden, with the assistance of Provector, and utilises a completely new bipolar lead-acid battery. In this case the battery was again fitted in four modules but because of the efficiencies of the battery design, was able to be fitted into the exact space utilised by the NiMH battery (Figure 2).

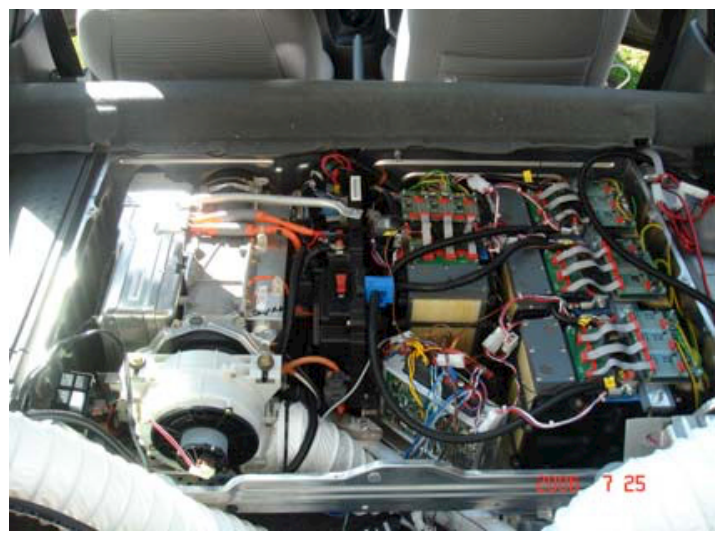

Figure 2: Effpower batterv in place

While this conversion has not been subjected to a formal test programme as was done with the RHOLAB battery, it is in regular road use in the Gothenburg area of Sweden and some time ago had covered over $30,000 \mathrm{~km}$ without any problems. 


\subsection{The UltraBattery Project}

The UltraBattery is a completely novel design of battery developed by the Commonwealth Scientific and Industrial Research Organisation (CSIRO) in Australia with the support of the ALABC. The novelty lies in the design of the negative plate which is part asymmetric supercapacitor and part conventional plate (Figure 3).

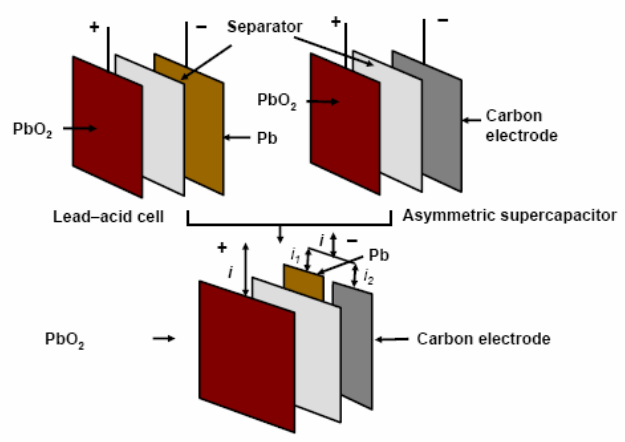

Figure 3: Schematic view of the UltraBattery

This gives the battery the ability to both deliver and receive charge at very high rates as required in an HEV battery. After some outstanding laboratory testing which showed the battery outperforming NiMH cells in HEV cycling tests (Figure 4), a set of batteries was obtained from their licensees Furukawa for road trials in an Insight acquired for the purpose.

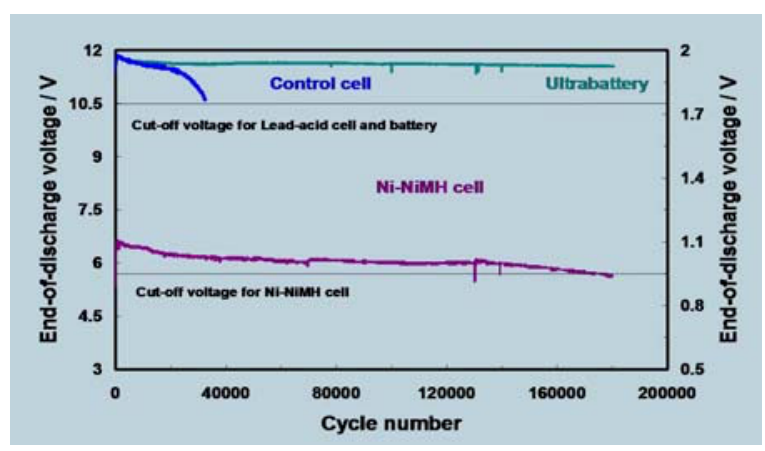

Figure 4: UltraBattery Cycling $\mathrm{v}$ NiMH under the EUCAR Power Assist Profile

Again the battery is relatively compact and was fitted as $12 \times 12 \mathrm{~V}$ modules into the exact space utilised by the $144 \mathrm{~V}$ NiMH battery (Figure 5).

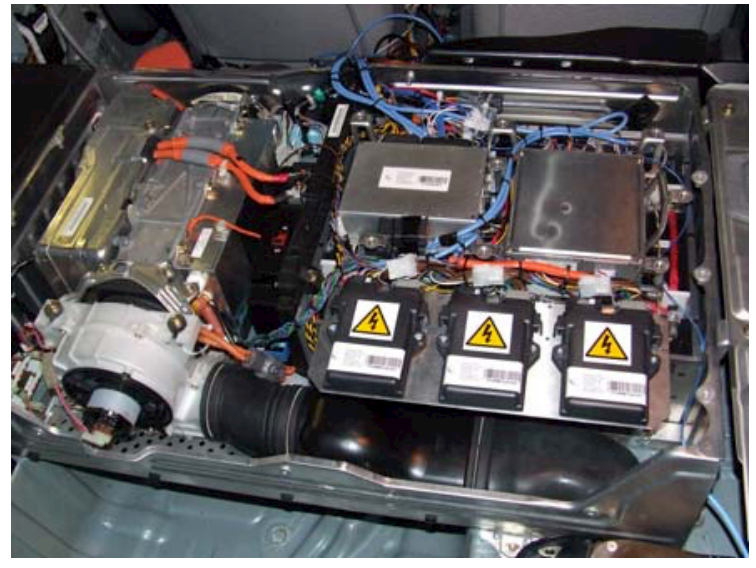

Figure 5: The UltraBattery in place

It started testing at Millbrook in April 2007 and is pictured in Figure 6 running with the RHOLAB vehicle.

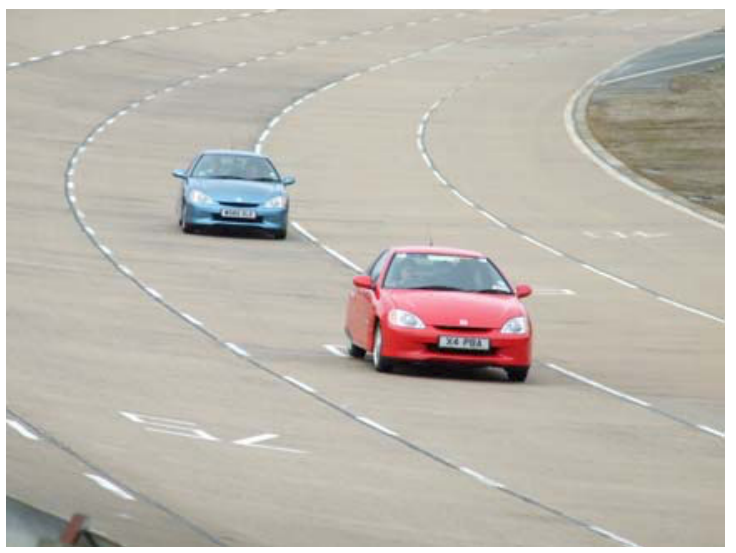

Figure 6: The RHOLAB (red) and UltraBattery (blue) Insights under test at Millbrook

With the combination of having a 'generation 2' battery and updated electronics, this vehicle performed outstandingly in its test - frequently running a three shift day with very stable battery voltages and temperature. In fact the vehicle reached its initial target of $80,000 \mathrm{~km}$ a day later than the RHOLAB car and without any equalisation or conditioning of the battery being carried out.

As a result of this performance, it was decided to extend the test to $160,000 \mathrm{~km}$ - way beyond normal warranty distance for the NiMH battery. This milestone for advanced lead-acid batteries was reached on January $15^{\text {th }} 2008$. Thus the vehicle had covered the $160,000 \mathrm{~km}$ in barely 9 
months. Also, at the end of the test, the battery had still not been equalised or conditioned.

\subsubsection{The Test Cycle}

As well as being equipped with the battery management system, the vehicle has very comprehensive data logging system, capturing information on items such as module voltage, current, state of charge and battery temperatures as often as four times per second. Data is also recorded from the vehicle's on-board diagnostic system (OBD) as well the Global Positioning System (GPS). Thus as well as recording any abnormalities in the data, it is possible to locate the vehicle's position and also how it was being driven - by looking at throttle position, engine $\mathrm{rpm}$ etc. By logging all this information, a massive amount of data has been obtained on how the battery behaves under the hybrid duty cycle. The actual test cycle used is a proven OEM motorway simulation driving cycle on the Millbrook high speed bowl. This is capable of moving the battery state-of-charge around as well as putting on the miles quickly to keep testing costs realistic. This test took place on the high speed bowl at Millbrook and Figure 7 shows a recorded GPS speed trace of the test.

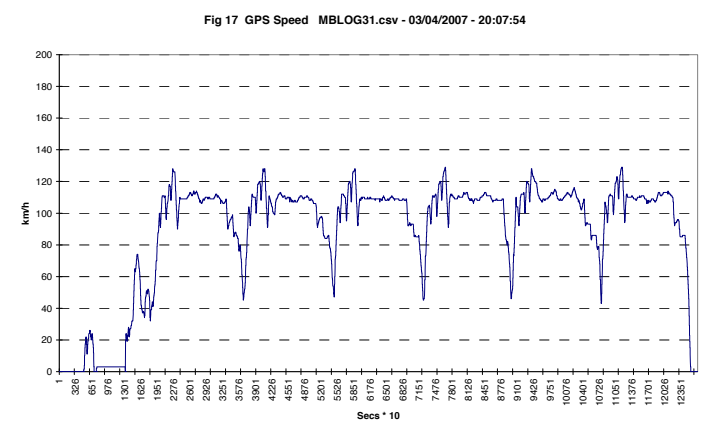

Figure 7: A GPS speed plot

The data monitoring has also been such that it has been easily possible to identify differences in driver skills in adhering to the test cycle - or, on occasions, where driver errors have resulted in issues with the vehicle.

\subsubsection{Typical Data}

Figure 8 shows module maximum and minimum voltages for each of the 12 modules plotted on top of each other during a run. It can be seen that the module voltages overlay each other well indicating uniform operation.

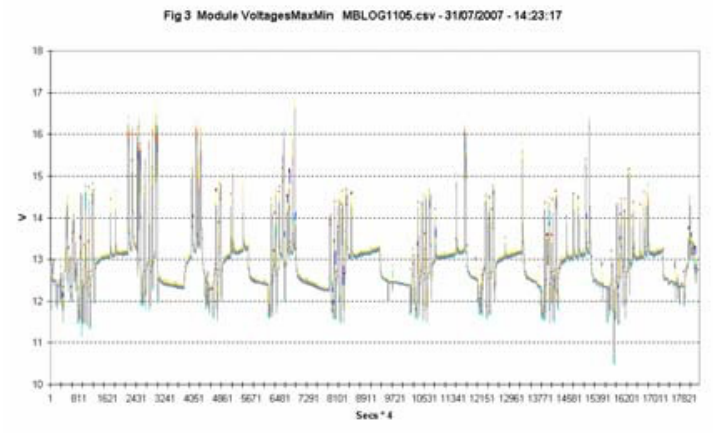

Figure 8: Maximum and minimum module voltages during a test

Figure 9 shows the maximum and minimum currents plotted in the same way while Figure 10 shows the state of charge of each of the 12 modules during a run.

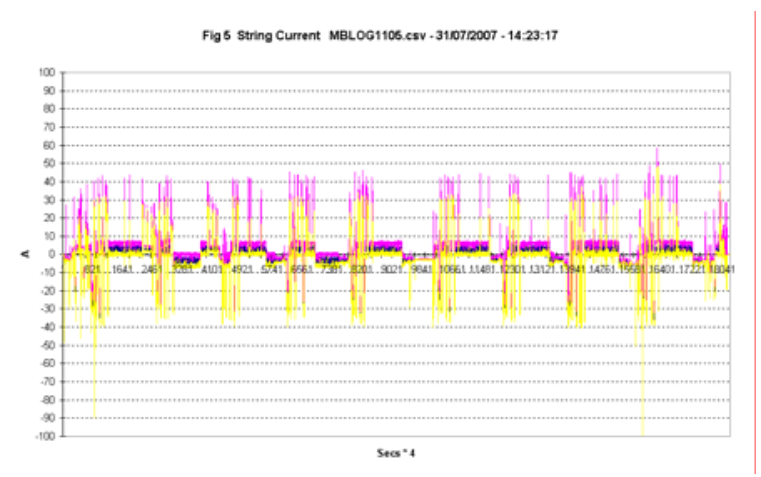

Figure 9: Maximum and minimum currents plotted during a test run. Assist currents are positive.

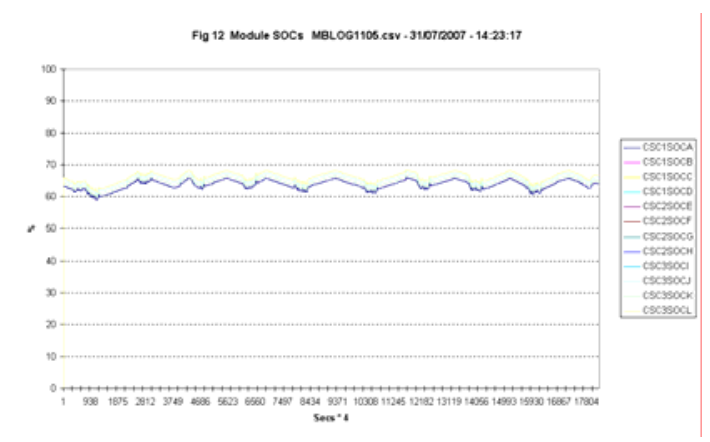

Figure 10: Variations in the state-of-charge of the modules during a test run

It is quite surprising how uniformly these are tracking as it is more common for batteries in a string to diverge in SoC quite rapidly as was discussed in the paper given to EET2007 [4] when 
the ISOTEST programme was presented. With this trial of the UltraBattery, the modules were within $1.5 \%$ of each other at the end of the test a truly remarkable result bearing in mind no equalization of the batteries took place at all.

The paper given at EET2007 [4] looked at the voltage $\mathrm{v}$ current plots for NiMH batteries as against the lead-acid batteries used in the RHOLAB modules. It was stated that a key objective in replacing the NiMH battery is to maintain a flat curve in these plots. This is particularly important if the control software in the vehicle's Motor Control Module cannot be modified, as in these projects, but also it is a measure of system efficiency. The curve for the standard Honda Insight NiMH battery recorded on an emissions test is shown in Figure 11.

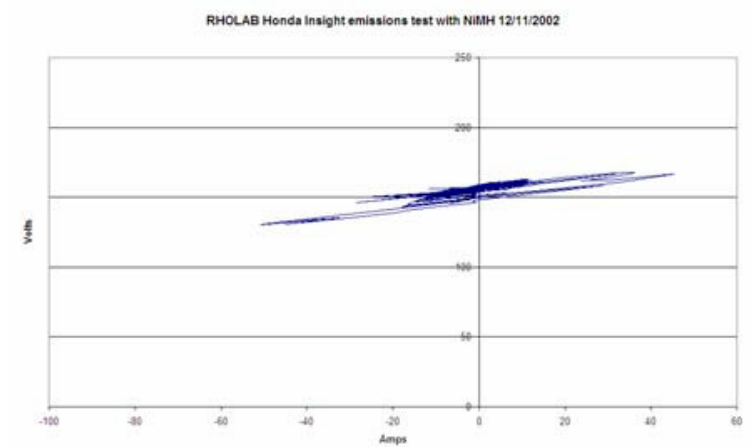

Figure 11: Voltage vs Current plot for a NiMH battery

It is interesting to look at comparable plots for the RHOLAB battery. When operated at a stateof-charge of around $70 \%$, the lead-acid battery exhibits higher voltages and a higher apparent impedance on charging as seen in Figure 12.

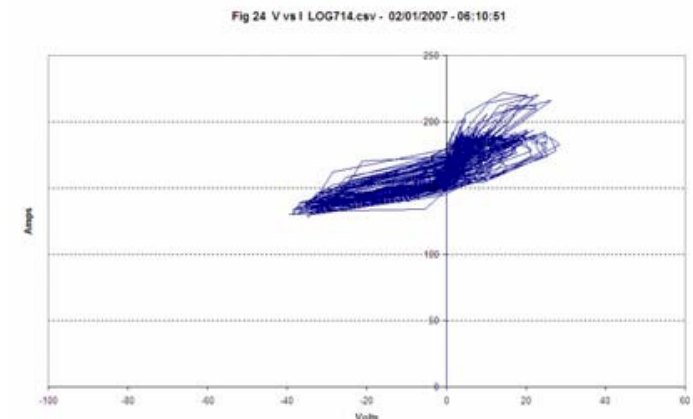

Figure 12: Voltage vs Current plot for the RHOLAB battery at $70 \%$ SoC

It is undesirable if the voltage exceeds $2.5 \mathrm{~V}$ per cell for more than a few seconds at a time as this can act to dry out the cell. However, when operated at a rather lower state-of-charge the RHOLAB cells have a characteristic which is very like the NiMH battery with no undesirable voltage peaks and a flat characteristic as seen in Figure 13.

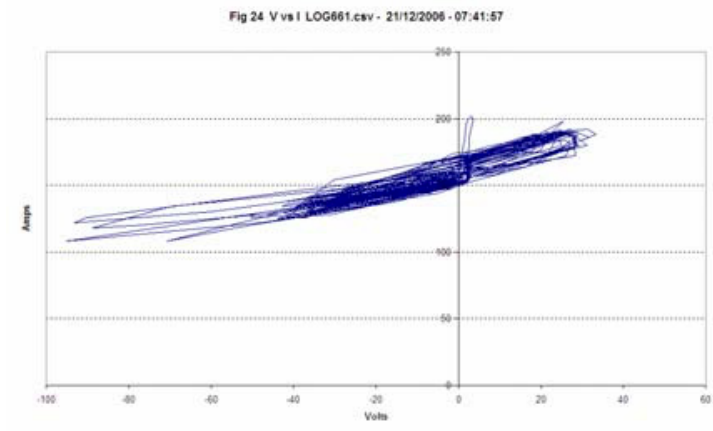

Figure 13: Voltage vs Current plot for the RHOLAB battery at $50 \%$ SoC

As can be seen in Figure 14, the characteristic curve for the UltraBattery is rather different in that there are voltage peaks during the recharge events. However, it is felt that one effect of the capacitive negative plate is to make the battery less susceptible to problems associated with these high voltages such as dry out. The curve is very flat over the rest of the current range, and on many occasions at high charge currents, and is much closer to NiMH behaviour than the earlier batteries.

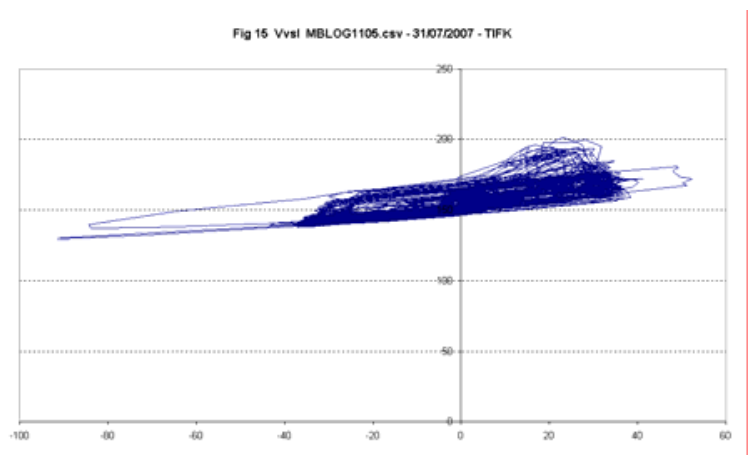

Figure 14: Voltage v Current plot for the UltraBattery at about $65 \%$ SoC

The vehicle ran well during the testing and no problems with the car during running were batteryrelated. The overall fuel consumption during the test was $4.73 \mathrm{l} / 100 \mathrm{~km}$ - a fraction under $60 \mathrm{mpg}$. It is not possible to relate this performance to the vehicle with the NiMH battery because, when the original RHOLAB car was investigated at 
Millbrook, it was to a different test cycle reflecting the need to gather a wide range of data in as short a period as possible.

\section{Current Work}

While the demonstrations of these three battery types have clearly shown that advanced lead-acid batteries are capable of the performance and life required in this HEV application - this model Insight is perhaps no longer seen as a current vehicle platform. In the period during which these tests were being carried out, NiMH technology has moved on and the batteries have been further optimized for power and are capable of higher rates of charge and discharge than experienced in the Insight.

The EALABC acquired during 2007 a new Honda Civic Hybrid and this had a NiMH battery of $158 \mathrm{~V} 5.5 \mathrm{Ah}$ as compared with the $144 \mathrm{~V}$ $6.5 \mathrm{Ah}$ in the Insights. The battery also fits compactly in the space between the rear seat and the luggage compartment. The initial investigation showed the battery recording extreme peak discharges of up to 130A (24C) and charge currents of 80A (15C) (Figure 15) as compared with the $15 \mathrm{C}$ and $8 \mathrm{C}$ recorded in the Insight.

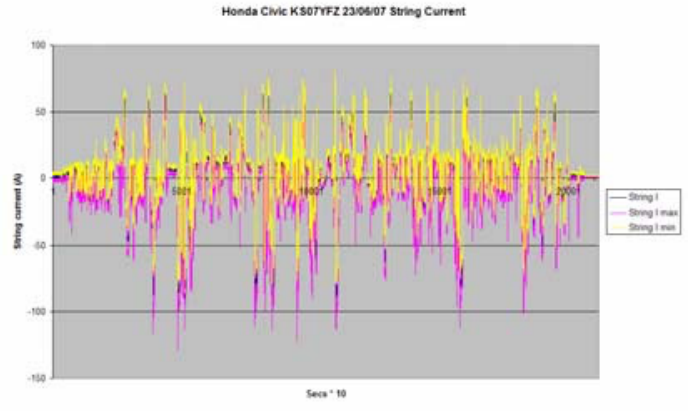

Figure 15: Current data recorded during hard driving the Honda Civic

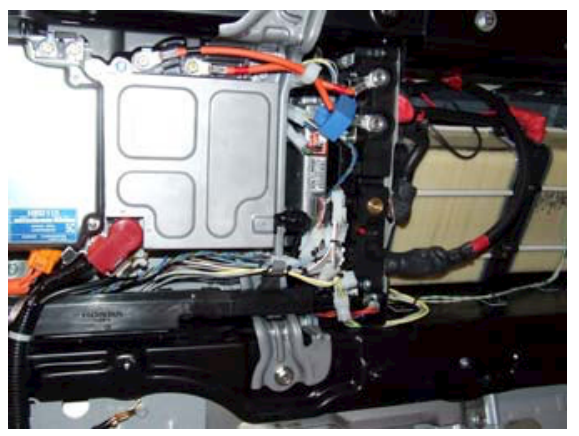

Figure 16: The Effpower bipolar battery (right) in the Civic
The vehicle was converted in Sweden to use an Effpower bipolar battery (Figure 16). In order to try and marry up with the Honda electronics, the battery was fitted in two blocks - one of $72 \mathrm{~V}$ and the other of $86 \mathrm{~V}$ - matching the $158 \mathrm{~V}$ of the original NiMH battery. This new battery has itself have been improved from the one used in the Insight discussed earlier to have its negative plate formulation modified with additional carbon as a result of ALABC research. As well as inhibiting the formation of lead sulfate in HEV operation, it also significantly enhances the ability of the battery to deliver and accept charge at high rates.

After initial shake-down work the car started testing at Millbrook at the beginning of March

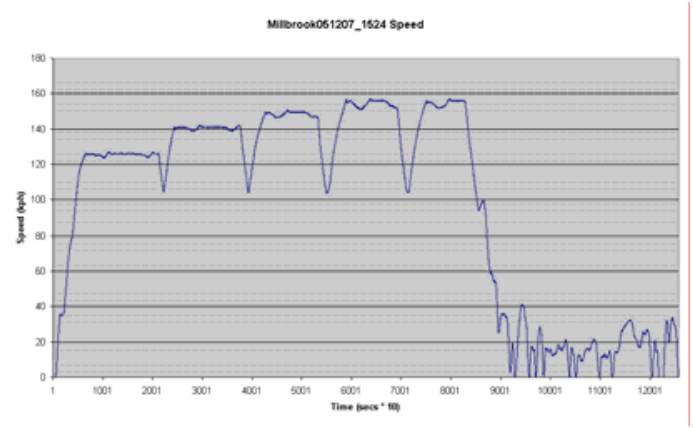

Figure 17: Speed plot of Civic test cycle

2008. It operated on a mix of aggressive high speed and city course running as indicated by the speed plot in Figure 17. The intention was to track test the vehicle for $40,00 \mathrm{~km}$ and in the meantime to carry out extended testing on a smaller module in the laboratory using a cycle derived from real data gained on the track.

The battery management system on the Honda is designed to protect the battery by limiting the over-voltage of the battery during regenerative charging. As NiMH is able to tolerate higher levels of overcharge than a typical VRLA battery and it was not possible to adjust the Honda electronics to reflect this - it was necessary to fit a voltage clamp to try and limit the voltage of the lead-acid battery to around $2.36 \mathrm{~V}$ per cell.

The vehicle completed the planned 40,000 $\mathrm{km}$ but there were signs of battery deterioration. There had been two failures of the voltage clamp which resulted in over-voltage of the battery. It was also apparent that the temperature of the battery had been considerably in excess of that planned and the voltage clamp had not been programmed to allow for this. As a result there was increased chemical 
activity in the battery leading to gassing at elevated temperatures when the voltage limit should have been lowered. It was also apparent that the lower amount of cooling in the centre cells of the modules aggravated these temperature problems. Tear-down results confirmed dry-out and sulfation in the battery.

In the meantime testing continued of the laboratory module and this completed cycling equivalent to $160,000 \mathrm{~km}$ without any problems. As a result of this successful test it has been decided to repeat the vehicle trials. For this next stage of the work, the voltage of the battery will be increased slightly for greater efficiency and less reliance on the voltage clamp, the battery will be split into smaller units for improved cooling and there will be improved temperature monitoring and linkage to battery voltage control.

Many of these problems result from having to demonstrate these batteries in vehicles which have electronics designed for different chemistries but nevertheless, it has been shown that advanced lead acid can perform very well in this application. It should also be noted that the ALABC has approved plans to try the UltraBattery in a Honda Civic in another project based in the USA.

\section{Summary}

Advanced lead-acid batteries have been shown to be a low cost option for hybrid electric vehicles. While it is always difficult to obtain definitive cost comparisons because of commercial sensitivities, some indications are occasionally made available in conference papers. For example, J. German in a paper given at $\mathrm{AABC}$ 08 , indicated a NiMH battery price of $\$ 2,000$ $\mathrm{kWh}$ [5]. At the same conference H. Takeshita indicated 'target' prices for Li-Ion at $\$ 900 \mathrm{kWh}$ but not yet realised [6].

Predictive prices for an advanced lead-acid battery of this size are in the region of $\$ 250-350$ per $\mathrm{kWh}$. Li-Ion battery prices may ultimately be lower than NIMH but the battery has to be managed at the cell level for safety reasons which add very complex electronics and cost. The recent tests with the advanced lead-acid batteries show this level of control not to be necessary.
Recycling issues are also relevant in that over $90 \%$ of lead-acid batteries are profitably recycled world wide into raw materials capable of being re-used in battery manufacture. This cannot be said to be true of competing chemistries.

Another factor frequently held against lead-acid is weight. While lead-acid does have a lower specific energy than both NIMH and Li-Ion batteries, its power density is very good. This programme has already demonstrated that the advanced lead-acid designs can be fitted into the same space as the original NiMH batteries. The same is also true of the Civic programme. What should also be remembered is that because NiMH batteries are notoriously bad in cold conditions it is necessary to provide a $12 \mathrm{~V}$ lead-acid battery, in addition to the DC to DC converter, in order to start the car in cold weather. With a lead-acid HEV battery in place this secondary battery probably becomes unnecessary, or at worst a small back-up battery may be necessary for some loads. With the removal of this battery and the unnecessary starter motor, the weight impact of the lead-acid HEV battery becomes almost neutral.

Thus the ALABC remains confident of the future of lead-acid batteries in this environment and is continuing its research and demonstration programmes to ensure that there are a range of different battery options available for the different hybrid types. In this way the cost of hybrid vehicles should reduce, making them more attractive to the consumer, and hence help in the fight to reduce emissions of greenhouse gases.

\section{Acknowledgments}

\section{RHOLAB}

This Project was carried out under the auspices of the Foresight Vehicle Programme with funding from the UK Department of Trade and Industry and from the Engineering and Physical Sciences Research Council. Additional funding was provided from the European Advanced Lead Acid Battery Consortium, the Hawker Batteries Group and Quexco Ltd. The contribution of all the project partners to success of the project is acknowledged. These were Hawker Batteries Ltd, Provector Ltd and the Universities of Sheffield and Warwick.

The partners would also like to thank Honda R\&D Europe (UK) Ltd for their assistance with this Project. 


\section{The Effpower Demonstrations}

The assistance of Effpower in providing batteries for the two demonstrations mentioned in this paper. The ALABC and EALABC have provided assistance through Provector Ltd in fitting and integrating these batteries into the vehicle. The ALABC is also funding the testing of the Honda Civic at Millbrook Proving Ground.

\section{The UltraBattery Demonstration}

This has been coordinated and funded by the EALABC and ALABC. The advice and assistance of CSIRO and Furukawa, the developers of the battery is acknowledged. The battery was fitted and integrated into the vehicle by Provector Ltd. Thanks are also due to the staff at the Millbrook Proving Ground in the UK for their advice and assistance during the testing of the car.

\section{References}

[1] Development of a lead-acid battery for a hybrid electric vehicle'. A Cooper, Journal of Power Sources 153 (2004) 116125.

[2] 'Development of a high performance leadacid battery for new generation vehicles', A Cooper, Journal of Power Sources, 144 (2005) 385-394.

[3] 'BMW EfficientDynamics powered by intelligent energy management'. C. Diegelmann et al, Advanced Automotive Battery Conference, Long Beach, USA, May 16-18, 2007.

[4] 'The demonstration of new generation lead-acid batteries in hybrid electric vehicles', A.Cooper, $\mathrm{M}$ Kellaway, B. Bonnet, J. Marco, N. Vaughan. EET 2007, Brussels, May 2007.

[5] 'Technical and Market Challenges for Vehicle Electrification, J German, AABC 08, Tampa, May 14-16, 2008

[6] 'Li-Ion Market Status and the Forecast for Automotive Applications', H Takeshita, AABC 08, Tampa, May 14-16, 2008.

\section{Authors}

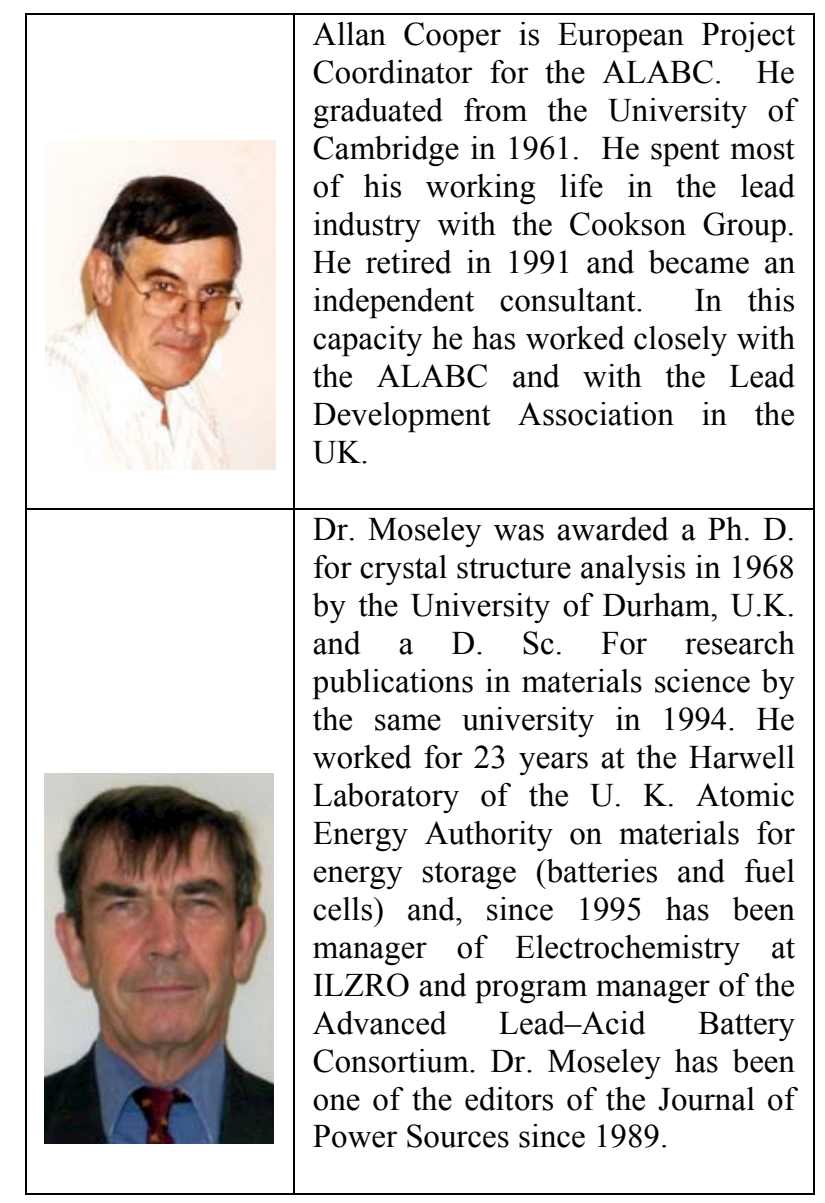

